\title{
Percepção de motoristas de Uber sobre condições de trabalho e saúde no contexto da Covid-19
}

\author{
Uber drivers perception about their work and health conditions in the \\ context of Covid-19
}

João Pedro Greggo', Sergio Roberto de Lucca', Valmir Azevedo', Marcia Bandini1

DOI: $10.1590 / 0103-1104202213206$

\begin{abstract}
RESUMO O trabalho mediado por plataformas como a Uber vende uma ideia ilusória de 'empreendedorismo' para descaracterizar vínculos trabalhistas, sem perder o controle sobre os motoristas. Na pandemia da Covid-19, motoristas de aplicativos arcaram com custos adicionais para adotar medidas de proteção para evitar o risco de contaminação pelo Sars-CoV-2. Estudo descritivo e comparativo conduzido a partir de uma amostra de conveniência com motoristas da plataforma Uber. O instrumento de pesquisa foi a aplicação virtual de questionário desenvolvido pelos pesquisadores com contribuições de representantes de associações e sindicato da categoria. De um grupo com cerca 500 motoristas Uber de grupos de WhatsApp, 104 motoristas participaram do estudo, dos quais 50\% tem jornadas de onze horas diárias ou mais e $24 \%$ trabalham sete dias por semana. Na pandemia, $79 \%$ referiram redução das horas trabalhadas, $96 \%$ diminuição da renda e 17\% tiveram sintomas compatíveis com Covid-19. Condições precárias de trabalho foram agravadas durante a pandemia, que ressaltou a vulnerabilidade do modelo de trabalho mediado por aplicativos. Esses trabalhadores são expostos a um trabalho inseguro, sem garantias pela empresa que os contrata, e ainda assumem todos os custos e riscos do exercício profissional. Esta pesquisa deu voz aos motoristas de aplicativos e, assim, pode contribuir para a melhoria de suas condições de trabalho.
\end{abstract}

PALAVRAS-CHAVES Condições de trabalho. Saúde do trabalhador. Emprego. Administração das tecnologias da informação.

ABSTRACT Work mediated by platforms such as Uber sells an illusory idea of 'entrepreneurship' to mischaracterize labor relations, without losing control over drivers. In the Covid-19 pandemic, Uber drivers had to handle with additional costs to adopt protective measures in order to avoid risks of contamination by Sars-CoV-2. Quantitative cross-sectional study based on a convenience sample with Uber drivers. The research instrument was a questionnaire developed by the researchers, with contributions from representatives of associations and unions. Out of 500 Uber drives in the WhatsApp groups, 104 drivers participated in the study, 50\% referred working-hours equal or above 11 daily hours, and $24 \%$ worked seven days a week. In the pandemic, 79\% reported a reduction in working hours, 96\% had a decreased income and $17 \%$ presented symptoms compatible with Covid-19. Poor working conditions were aggravated during the pandemic that highlighted the vulnerability of the application-mediated work model. These drivers are exposed to unsafe work conditions, with no guarantees by the hiring company, and also assume all costs and risks of their professional practice. This study gave voice to these drivers and, thus, it can contribute to propose improvements of their working conditions.

1 Universidade Estadual de Campinas (Unicamp) Campinas (SP), Brasil. mbandini@unicamp.br
KEYWORDS Working conditions. Occupational health. Employment. Information technology management. 


\section{Introdução}

Desde os anos 1970, a globalização e o desenvolvimento das Tecnologias de Informação e Comunicação (TIC) aceleraram o processo global de precarização do trabalho, com redução de direitos trabalhistas conquistados pelos trabalhadores ao longo do tempo. $\mathrm{O}$ trabalho mediado por plataformas digitais tais como a Uber, pioneira d esse processo de empresas operadas por algoritmos, vende para o trabalhador uma ideia ilusória de 'empreendedorismo' para descaracterizar os vínculos trabalhistas, sem perder o controle sobre esse auto gerente- subordinado ${ }^{1}$, que adere à plataforma digital como forma de sobrevivência.

Nessa condição, além de não possuírem qualquer suporte ou vínculo que garanta acesso a direitos trabalhistas, trabalhadores e trabalhadoras 'uberizados' assumem todos os riscos e custos de sua atividade profissional e acabam reféns de uma remuneração variável por demanda. Horas de espera por uma corrida não são pagas e, dessa forma, os motoristas se tornam trabalhadores just-in-time 1-4 $^{\mathbf{- 4}}$.

Nessa nova organização de trabalho flexibilizado, as empresas detêm toda a tecnologia para organizar a oferta de 'empreendedores' disponíveis e a demanda de clientes, em uma forma virtual de subordinação e controle sobre o trabalho'.

Em empresas como a Uber, o gerenciamento virtual, o controle e a vigilância do trabalho ocorrem por meio das programações algorítmicas, reforçando uma falsa sensação de que há uma mediação, um gestor do serviço ao cliente. Entretanto, é a empresa que contrata o 'empreendedor', mediante a exigência de seguro do veículo, definição do valor do serviço ou remuneração e, ainda, demite ou bloqueia definitivamente o motorista em função da avaliação dos clientes e se exime de apresentar justificativas pela decisão. A Uber detém total controle sobre a distribuição do trabalho, assim como a determinação do valor das corridas, transformando sua autonomia do 'parceiro empreendedor' em uma ilusão'.
Além de se responsabilizarem por todos os custos para exercer sua atividade laboral, os motoristas de aplicativos são reféns de serem avaliados negativamente pelo cliente e sofrerem suspensão ou bloqueio temporário ou definitivo da plataforma, o que também pode acontecer caso haja rejeição de muitas corridas. Nesse processo, retira-se a autonomia e o poder de decisão do motorista sobre o seu trabalho ${ }^{\mathbf{1 , 5}, \mathbf{6}}$.

Para evitar o bloqueio devido à avaliação negativa dos clientes, é exigido um ótimo padrão de atendimento aos passageiros em todas as viagens, incluindo o ar-condicionado sempre ligado, disponibilidade de balas e água, manter o carro sempre limpo e aspirado por dentro, conseguindo, assim, manter a sua nota acima de $4,6^{7}$.

Na pandemia da Covid-19, os motoristas de aplicativos tiveram que arcar com custos adicionais para adotar medidas de proteção para evitar a exposição e o risco de contaminação pelo Sars-CoV-2, considerando-se o ambiente fechado do veículo. Não havendo qualquer compensação por parte da empresa, os rendimentos foram ainda mais comprometidos.

Além do risco de contaminação dos motoristas, a pandemia também evidenciou a precariedade do trabalho por aplicativos no tocante à falta de regulação de direitos trabalhistas, de saúde ocupacional e de proteção social. Nesse contexto, este estudo teve como objetivo descrever o perfil biossocial dos motoristas de aplicativos - suas características demográficas, sociais e de trabalho - e o impacto da pandemia da Covid-19 nessa categoria profissional.

\section{Metodologia}

Trata-se de estudo descritivo comparativo a partir de amostra de conveniência de um grupo de motoristas da plataforma Uber vinculado às seguintes entidades: Associação dos Motoristas por Aplicativo Autônomo de São Carlos e Região (Amasc), Associação dos Motoristas de Aplicativo de Campinas e Região (Amacre) 
e Sindicato dos Trabalhadores com Aplicativos de Transportes Terrestres Intermunicipal do Estado de São Paulo (STATTESP).

$\mathrm{O}$ instrumento de pesquisa foi desenvolvido pelo pesquisador responsável contemplando as seguintes etapas: (1) desenvolvimento do instrumento preliminar de pesquisa a partir do levantamento da literatura sobre o tema do estudo; (2) apresentação e discussão da versão preliminar com representantes das associações e do sindicato envolvidos; (3) elaboração da versão final do questionário de pesquisa; (4) inclusão do instrumento de pesquisa no software Google Forms ${ }^{\circledast}$. As questões do referido questionário abordaram aspectos gerais referentes aos objetivos propostos, conforme descrição no quadro 1 .

\begin{tabular}{|c|c|}
\hline Tema & Variáveis analisadas \\
\hline Dados sócio-demográficos & $\begin{array}{l}\text { Idade, sexo, estado civil, raça-etnia, grau de escolaridade, se estuda } \\
\text { atualmente, ocupação principal, cidade onde trabalha, número de } \\
\text { dependentes. }\end{array}$ \\
\hline Trabalho como motorista de aplicativo & $\begin{array}{l}\text { Tempo de trabalho com a Uber, horas trabalhadas por dia no aplica- } \\
\text { tivo, dias da semana em que trabalha, trabalho com outro aplicativo, } \\
\text { trabalho fora dos aplicativos, gastos com o veículo, influência do } \\
\text { trabalho na convivência familiar, satisfação com o trabalho, violência } \\
\text { durante o trabalho. }\end{array}$ \\
\hline Aspectos relacionados à saúde e previdência & $\begin{array}{l}\text { Contribuição com o INSS, contribuição com previdência privada, se } \\
\text { possui plano de saúde, acidente no trabalho, incapacidade para o } \\
\text { trabalho (relacionado ao acidente), utilização do SUS, problema de } \\
\text { saúde (diabetes, hipertensão arterial, dislipidemia, outras doenças). }\end{array}$ \\
\hline Trabalho durante a pandemia de Covid-19 & $\begin{array}{l}\text { Diminuição da renda (em porcentagem), uso de máscaras e ou- } \\
\text { tros equipamentos de proteção individual, medidas adotadas para } \\
\text { higienização do veículo, contato próximo com caso suspeito e/ou } \\
\text { confirmado de Covid-19, se teve diagnóstico positivo de Covid-19 } \\
\text { (trabalhador). }\end{array}$ \\
\hline Questões abertas & $\begin{array}{l}\text { Foram incluídas quatro questões abertas sobre o que motivou ser um } \\
\text { motorista de aplicativo e quais são os aspectos positivos e quais são } \\
\text { os pontos negativos do trabalho e o que poderia melhorar em seu } \\
\text { trabalho como motorista de aplicativo. }\end{array}$ \\
\hline
\end{tabular}

Fonte: elaboração própria.

O pesquisador responsável foi temporariamente incluído, pelos respectivos representantes, nos grupos de WhatsApp ${ }^{\circ}$ vinculados a STATTESP, Amasc e Amacre, para o envio do link do questionário (Google Forms ${ }^{\circledast}$ ). De cerca de 500 motoristas, 104 participantes responderam o questionário após a leitura do Termo de Consentimento Livre e Esclarecido (TCLE). Os dados permaneceram anônimos para conservar a confidencialidade dos participantes.
O questionário via Google Forms e a forma de acesso via WhatsApp ${ }^{\circledast}$ adotados nesta pesquisa possibilitaram ao pesquisador o contato direto com os participantes em um ambiente informal durante a pesquisa de campo.

A pesquisa foi realizada no período de 17/9/2020 a 4/12/2020 e os dados obtidos foram exportados para uma planilha Excel ${ }^{\oplus}$ descritiva.

$\mathrm{O}$ projeto de pesquisa foi aprovado pelo Comitê de Ética e Pesquisa (CAAE $-36043120.1 .0000 .5404)$. 


\section{Resultados}

Dos cerca de 500 integrantes dos grupos de WhatsApp, o estudo obteve 104 (20,8\%) respostas na íntegra para o instrumento de pesquisa.

Dos 104 (100\%) participantes, 16 (15,4\%) tinham 30 anos ou menos e a faixa etária predominante foi de 31 a 50 anos $(65,4 \%)$. A maioria dos participantes é do sexo masculino $87(83,7 \%)$ e $83(79,8 \%)$ são casados/as.

A metade dos respondentes (52,5\%) tinha o ensino médio completo. Entretanto, observou-se grande diversidade de escolaridade entre os motoristas, inclusive com curso superior e pós-graduação.

Os dados que representam o perfil biossocial dos entrevistados estão relatados na íntegra na tabela 1.

Tabela 1. Perfil biossocial dos motoristas e aplicativo entrevistados

\begin{tabular}{|c|c|c|}
\hline Idade & $\mathbf{N}$ & $\%$ \\
\hline Menor ou igual a 30 & 16 & 16 \\
\hline 31 a 40 & 34 & 32,7 \\
\hline 41 a 50 & 34 & 32,7 \\
\hline 51 a 60 & 15 & 15 \\
\hline Maior que 61 & 5 & 5 \\
\hline \multicolumn{3}{|l|}{ Sexo } \\
\hline Masculino & 87 & $84 \%$ \\
\hline Feminino & 17 & $16 \%$ \\
\hline \multicolumn{3}{|l|}{ Situação marital } \\
\hline Casado/União estável & 83 & $80 \%$ \\
\hline Solteiro & 12 & $12 \%$ \\
\hline Divorciado & 9 & $9 \%$ \\
\hline Viúvo & 0 & $0 \%$ \\
\hline \multicolumn{3}{|l|}{ Raça } \\
\hline Branca & 56 & $54 \%$ \\
\hline Parda & 37 & $36 \%$ \\
\hline Preta & 6 & $6 \%$ \\
\hline Indígena & 2 & $2 \%$ \\
\hline Amarela & 2 & $2 \%$ \\
\hline Não desejo informar & 1 & $1 \%$ \\
\hline \multicolumn{3}{|l|}{ Escolaridade } \\
\hline Médio completo & 52 & $50 \%$ \\
\hline Superior completo & 25 & $24 \%$ \\
\hline Pós- graduação & 10 & $10 \%$ \\
\hline Fundamental incompleto & 9 & $9 \%$ \\
\hline Fundamental completo & 8 & $8 \%$ \\
\hline
\end{tabular}


Ser motorista de aplicativo é a ocupação principal para 87 (83,7\%) dos entrevistados, enquanto que para os demais este tipo de trabalho representa uma renda extra.

Com relação ao tempo de trabalho nessa modalidade de trabalho, um importante contingente dos respondentes ( $45 ; 43,3 \%)$ ingressou há menos de dois anos; 35 (36,5\%) trabalham com aplicativos de três a cinco anos; e dois (1,9\%) estão há mais de 5 anos.

Metade dos motoristas (52; 50\%) relataram trabalhar onze horas ou mais por dia e $96(92,3 \%)$ trabalham entre cinco a sete dias na semana. Em virtude das longas jornadas de trabalho, 38 (36,5\%) dos motoristas referiram que sua convivência familiar foi afetada frequentemente.

Quanto ao empregador, 88\% referiram trabalhar com outros aplicativos além da Uber, e quase todos (99\%) trabalhavam para a empresa 99. Para $85 \%$ dos respondentes, o trabalho como motorista de aplicativo é a renda principal e é renda exclusiva para $49 \%$ dos participantes.

O desgaste do veículo foi evidenciado pela distância percorrida por semana e dos entrevistados, $41(39,4 \%)$ relataram rodar entre 1.001 e $2.000 \mathrm{~km}$ por semana. Os gastos com manutenção do veículo superaram os $\mathrm{R} \$ 1.000$ reais mensais para 78 (75\%) dos motoristas, como pode ser observado na tabela 2.

\begin{tabular}{|c|c|c|}
\hline Características do trabalho & Variável & $(\%)$ \\
\hline \multirow[t]{2}{*}{ Ocupação principal (referida) } & Motorista de aplicativo & 85 \\
\hline & Outras & 15 \\
\hline \multirow[t]{3}{*}{ Veículo } & Próprio financiado & 56 \\
\hline & Próprio quitado & 28 \\
\hline & Alugado & 15 \\
\hline \multirow[t]{4}{*}{ Tempo de trabalho como motorista de aplicativo } & Menos de 1 ano & 18 \\
\hline & 1 a 2 anos & 43 \\
\hline & 3 a 5 anos & 37 \\
\hline & Mais que 5 anos & 2 \\
\hline \multirow[t]{4}{*}{ Horas diárias de trabalho } & 1 a 5 horas & 10 \\
\hline & 6 a 10 horas & 40 \\
\hline & 11 a 12 horas & 23 \\
\hline & Mais que 12 horas & 27 \\
\hline \multirow[t]{3}{*}{ Dias de trabalho na semana } & 1 a 4 dias & 8 \\
\hline & 5 a 6 dias & 68 \\
\hline & 7 dias & 24 \\
\hline \multirow[t]{4}{*}{ Distância média percorrida por semana (em Km) } & Menos de 500 km & 12 \\
\hline & 501 a 1000 km & 40 \\
\hline & 1001 a 2000 km & 39 \\
\hline & Mais que 2001 km & 9 \\
\hline \multirow[t]{5}{*}{ Renda como motorista de aplicativo, em relação à renda total } & Menos de $30 \%$ & 9 \\
\hline & De 30 a $50 \%$ & 14 \\
\hline & De 51 a $70 \%$ & 15 \\
\hline & De 71 a $99 \%$ & 13 \\
\hline & $100 \%$ & 49 \\
\hline
\end{tabular}


Tabela 2. (cont.)

\begin{tabular}{lcr}
\hline Características do trabalho & Variável & (\%) \\
\hline Gastos mensais com o veículo (em R\$) & Menos de 500 & 13 \\
& De 501 a 1000 & 13 \\
& De 1001 a 1500 & 29 \\
& De 1501 a 2000 & 13 \\
\hline
\end{tabular}

Fonte: elaboração própria.

A satisfação com o trabalho foi avaliada pelo próprio motorista em uma escala de 0 a 10 , sendo 10 a melhor avaliação. A média obtida foi de 6,18. Considerando como aprovação uma nota acima de 6 , o estudo mostrou que $64 \%$ dos motoristas estão satisfeitos com seu trabalho, apesar das dificuldades referidas em questões anteriores. Quando indagados sobre o quão satisfeitos os motoristas se sentem em relação aos passageiros, a aprovação chegou a $81 \%$, com nota média de 7,24 .
A segurança no trabalho foi informada como a maior preocupação dos motoristas, e 92 (88,5\%) consideraram que seu trabalho é pouco ou nada seguro. Mais da metade $53(51 \%)$ relatou já ter sofrido algum tipo de violência durante sua atividade laboral e 89 (85,6\%) conheciam algum(a) colega que já sofreu violência no trabalho. Em relação aos acidentes de trabalho, $32(30,8 \%)$ afirmaram já terem sido vítimas e 84 (80,8\%) conheciam algum colega vítima, conforme descrição na tabela 3.

Tabela 3. Informações sobre a segurança dos motoristas de aplicativos ( $n=104)$

\begin{tabular}{lrr}
\hline Segurança - como motorista de aplicativo & Quantidade & Porcentagem \\
\hline Pouco seguro & 48 & $46 \%$ \\
Nada seguro & 44 & $42 \%$ \\
Muito seguro/Seguro & 12 & $12 \%$ \\
\hline Sofreu violência - como motorista de aplicativo & & $51 \%$ \\
\hline Sim & 53 & $49 \%$ \\
Não & 51 & $42 \%$ \\
\hline Tipo de violência - como motorista de aplicativo & & $24 \%$ \\
\hline Agressão verbal & 44 & $22,11 \%$ \\
Vandalismo do veículo & 25 & $18,26 \%$ \\
Assédio sexual & 23 & $3,84 \%$ \\
Roubo/furto & 19 & $3,84 \%$ \\
Agressão física & 4 & 4 \\
Outros & & \\
\hline
\end{tabular}

Fonte: elaboração própria. 
Dos participantes, 52 (50\%) contribuem com a previdência social e, em sua maioria, são inscritos como Microempreendedores Individuais (MEI). Outros 10 (9,6\%) contribuem para uma previdência privada.

Quanto aos cuidados com a saúde, 57 (54,8\%) referem não possuir problemas de saúde, 79 (76\%) não possuem plano de saúde privado e usam exclusivamente o Sistema Único de Saúde (SUS), mas a maioria $62(59,6 \%)$ não faz acompanhamento de saúde de rotina. Entre os que relataram ter algum problema de saúde, 16 participantes referiram hipertensão arterial, 16 se consideravam obesos e nove referiram diabetes.

A maioria dos motoristas 70 (67,3\%) referiu a manutenção do trabalho durante a pandemia de Covid-19, dos quais 21 (30\%) permaneceram trabalhando durante todos os dias da semana. Entre os participantes, 55 (78,6\%) relataram redução significativa das horas trabalhadas na pandemia, e, desses, treze (23,6\%) motoristas relataram diminuição de $30 \%$ de horas trabalhadas, 18 (32,7\%) diminuição em $50 \%$ e 24 (43,6\%) relataram diminuição de mais de $50 \%$ de horas trabalhadas. Como consequência, 67 (96\%) dos trabalhadores tiveram diminuição de renda pessoal ou familiar, o que levou $75(72,1 \%)$ deles a solicitar o auxílio emergencial oferecido pelo governo, embora apenas 51 (49\%) tenha conseguido obter o auxílio.

Com relação às medidas de proteção para prevenir a Covid-19, todos os motoristas informaram que, por conta própria, passaram a usar máscaras ao levar passageiros no veículo e $96 \%$ intensificaram a higienização do automóvel, com disponibilização de álcool em gel 70\% para os passageiros, além de aumentarem a frequência de lavagens do veículo.

A tabela 4 mostra que, quando perguntados sobre sintomas de Covid-19, 17 (16,3\%) dos motoristas referiram sintomas compatíveis, mas apenas seis (4\%) tiveram seu diagnóstico confirmado por exames. Desses, três solicitaram o auxílio oferecido pela Uber para motoristas que precisassem de afastamento do trabalho por conta da Covid-19. Nenhum requerente obteve o benefício da empresa.

Tabela 4. Impactos da pandemia no trabalho dos motoristas de aplicativos ( $\mathrm{n} 104$ )

\begin{tabular}{lcr}
\hline Característica & Variável & (\%) \\
\hline Trabalha desde o início da pandemia & Sim & 67 \\
\hline Teve sintomas de Covid-19 & Não & 33 \\
\hline Teve Covid-19 confirmada & Não & 17 \\
\hline Redução de horas trabalhadas & Sim & Não \\
\hline Porcentagem de redução de horas & Sim & 74 \\
& Não & 21 \\
\hline Redução da renda & Até 30\% & 24 \\
& Entre 31 e 50\% & 33 \\
\hline Porcentagem de redução de renda & Mais de 50\% & 44 \\
\hline
\end{tabular}


Tabela 4. (cont.)

\begin{tabular}{lrr}
\hline Característica & Variável & (\%) \\
\hline Uso de máscara ao levar passageiro & Sim & 100 \\
& Não & 0 \\
\hline Uso de álcool em gel 70\% & Sim & 100 \\
& Não & 0 \\
\hline Uso de película de isolamento & Sim & 13 \\
& Não & 87 \\
\hline Limpeza adicional do veículo & Sim & 96 \\
& Não & 45 \\
\hline
\end{tabular}

Fonte: elaboração própria.

As questões abertas ofereceram espaço para que os participantes da pesquisa levantassem aspectos positivos e negativos de seu trabalho que considerassem relevantes sobre suas motivações para trabalharem como motoristas de aplicativos, e sobre como suas condições laborais poderiam ser melhores.

Quanto aos aspectos positivos de seu trabalho, os participantes destacaram a flexibilidade de horário (45\%), complementação de renda ou remuneração (35\%) e ausência de chefe (10\%). Como aspectos negativos foram informados a falta de segurança (66\%), baixa remuneração (44\%), ausência de vínculo empregatício (13\%) e falta de autonomia (10\%).

Perguntados sobre o que poderia melhorar suas condições de trabalho, os participantes destacaram o valor das tarifas (66\%), a segurança (63\%) e ter maior autonomia (8\%).

\section{Discussão}

As mudanças no trabalho e nos modos de produção alavancados pela globalização e novas tecnologias produziram maior segmentação de mercados e da distribuição dos polos produtivos entre países centrais e periféricos, agravando o desemprego estrutural, especialmente nos países periféricos, e o crescimento do trabalho informal e do trabalho autônomo ${ }^{\mathbf{8}, 9}$.

De acordo com a Pesquisa Nacional por Amostra de Domicílios Contínua (PNAD Contínua), o ano de 2019 revelou a maior taxa de informalidade desde 2016, alcançando $41,1 \%$ da população economicamente ativa ${ }^{10}$, ou seja, quatro em cada dez trabalhadores estavam na situação de uma ocupação informal, sem proteção social11.

Comparando o primeiro trimestre de 2020 com o mesmo período de 2016, a PNAD contínua mostrou um aumento de 1,39 para 2,02 milhões de trabalhadores que atuam em aplicativos - um acréscimo de $41,9 \%^{10}$. Esse crescimento é um reflexo do aumento do desemprego e do trabalho informal, quadro agravado na pandemia.

\section{Do perfil biossocial}

Segundo o 'Correio Brazilense'12, a média de idade dos motoristas é 40 anos, e apenas 10,5\% apresentam ensino superior.

O resultado desta pesquisa indicou que 35 (34\%) entrevistados possuem ensino superior completo $(25 ; 24 \%)$ ou, ainda, pós-graduação (10; 9,6\%). O elevado nível de escolaridade pode indicar a tendência de que o desemprego atinge todos os níveis de instrução da força de trabalho. 
Os resultados obtidos mostraram pouca participação da mulher entre motoristas de aplicativos (17; 16,3\%). Fallavena ${ }^{\mathbf{1 3}}$ destaca em seu estudo as questões de gênero que atribuem às mulheres as atividades domésticas e de cuidado dos familiares, além da insegurança e de demandas pessoais ou associadas aos seus relacionamentos.

De fato, de acordo com a empresa Uber, as mulheres representam somente $6 \%$ dos 600 mil motoristas cadastrados. A segurança pessoal e o medo de assalto são os fatores que mais influenciam na tomada de decisão na hora da escolha desse tipo de empreendimento ${ }^{\mathbf{1 4}}$, além dos riscos de assédio, ofensas e desconfianças às quais essas trabalhadoras estão expostas 5 .

Com o objetivo de atrair as mulheres 'parceiras do negócio', a Uber criou 'Elas na Direção', com o slogan incentivo para que mais mulheres assumam a direção das suas vidas e tenham novas alternativas de renda, com a opção de receberem somente chamadas de passageiras mulheres ${ }^{15}$. Características femininas tais como prudência, empatia e cuidado ao volante são fatores que atraem parcela dos clientes, os quais preferem as motoristas devido a maior percepção de segurança ${ }^{5}$.

\section{Tempo de trabalho como motorista de aplicativo}

No início do processo de credenciamento, o 'motorista-parceiro' interessado precisa enviar documentos como a Carteira Nacional de Habitação (CNH) com a observação 'exerce atividade remunerada' e o seguro de acidentes pessoais para os passageiros, ou seja, as empresas de aplicativos definem as regras de admissão, mas transferem ao trabalhador a responsabilidade e custos pelo seguro do seu veículo e de terceiros ${ }^{16,17}$.

Este estudo mostrou que os motoristas começam sua atividade endividados, dado que 63 (70,2\%) dos entrevistados já iniciam o mês com o boleto de pagamento do financiamento ou aluguel do veículo para exercer sua atividade laboral, sem garantias de que receberão o suficiente para quitar suas contas para o exercício da função.

Os custos de manutenção são significativos. Considerando limpeza, lavagem, seguro, combustível, manutenção, financiamento e aluguel do carro, o custo médio foi de $\mathrm{R} \$ 1.200,00$ mensais, sendo que 28 (27,5\%) dos motoristas referiram gastos superiores a $\mathrm{R} \$ 2.000,00$ mensais com o veículo. Um fator que aumenta tais custos é a distância percorrida por semana, que pode chegar até $2.000 \mathrm{~km} / \mathrm{semana}$. Para aumentar seus ganhos, visto que a remuneração está parcialmente relacionada ao quilômetro rodado e ao tempo do percurso com o passageiro, os motoristas tendem a trabalhar mais tempo, rodando distâncias cada vez maiores.

Apesar das longas jornadas e altos custos, a satisfação média em relação ao trabalho foi de 6,18, em uma escala proposta pelos pesquisadores de 0 a 10, sendo 10 o maior grau de satisfação. A satisfação dos motoristas com os clientes foi maior, com média de 7,24.

A nota de satisfação do cliente é um dos itens que avalia o motorista, para que ele não seja banido do sistema da empresa ${ }^{\mathbf{1 8}}$. Portanto, essas notas sofrem o viés subjetivo dos clientes e do próprio algoritmo, fazendo com que a avaliação individual de desempenho os motoristas de aplicativos seja refém desse sistema cliente-algoritmo. A aparente autonomia do motorista por aplicativo é uma falácia, considerando-se que, nessa avaliação, ele é impedido de interagir, e o resultado unilateral do desempenho determina a continuidade no negócio ou o bloqueio. Esse sistema de métricas subjetivas advindas dos clientes ou do algoritmo gera uma pressão constante e crescente sobre os trabalhadores, desconstruindo o discurso recorrente de que o trabalhador 'uberizado' é seu 'próprio chefe'19.

\section{Segurança no trabalho}

No Brasil, dados do Observatório Nacional de Segurança Viária (ONSV) ${ }^{\mathbf{2 0}}$ revelam que uma pessoa morre vítima de violência no trânsito a 
cada doze minutos, ou seja, cinco mortes a cada hora ${ }^{21}$. Os estados que apresentam índices mais elevados de mortalidade por violência são, de maneira geral, também aqueles que apresentam os índices mais elevados de mortalidade no trânsito, sugerindo que ambos os casos sejam advindos de questões sociais.

Sobre cobertura na ocorrência de acidentes, o 'motorista parceiro' assume todos os custos de um seguro de acidentes pessoais para os passageiros e o próprio veículo. No caso de um acidente, para a empresa Uber, o seguro cobre apenas acidentes que ocorram durante uma viagem em que o motorista aceitou o passageiro em seu aplicativo e desloca-se para buscá-lo até o momento em que o deixa em seu destino21. Se o motorista que está se deslocando para casa ou para um local mais central sofrer um acidente, não haverá qualquer cobertura por parte da empresa.

Além do risco de acidente de trânsito, há o risco de assaltos durante o exercício da atividade laboral. Segundo dados da Secretaria de Segurança Pública (SSP), o número de motoristas assaltados no estado de São Paulo aumentou $80,2 \%$ no período entre janeiro e setembro de 201922,23. Tal dado que corrobora para a percepção de insegurança referida neste estudo, onde 48 (46,2\%) dos motoristas consideraram o trabalho pouco seguro, 44 (42,3\%) nada seguro e mais da metade $(53 ; 51 \%)$ dos entrevistados já relataram ter sofrido algum tipo de violência como motorista de aplicativo, demonstrando que a segurança é um ponto crucial a ser destacado nesta pesquisa.

A insegurança no trabalho e no trânsito, o risco de assalto pelos próprios passageiros e até mesmo de perderem a vida durante o trabalho foram indicados como aspectos negativos do trabalho pela maioria (66\%) dos respondentes.

No estado de São Paulo, levantamento feito pela polícia mostrou que $27 \%$ dos sequestros relâmpagos envolveram motoristas de aplicativo entre janeiro de 2019 e setembro de $2020^{24}$. Acontecimentos como esses, que permeiam a rotina de trabalho, contribuem para a insegurança desses trabalhadores e, frequentemente, viram manchete nos noticiários de todo o País: "Motorista de Uber é sequestrado e assaltado por falsos passageiros" 25 .

\section{Trabalho na pandemia da Covid-19}

Segundo o Observatório Social da Covid-19 da Universidade Federal de Minas Gerais (UFMG) ${ }^{25}$, as análises mostraram que, na pandemia, houve perda significativa de rendimento para os motoristas de aplicativos e que, diante do distanciamento social que reduziu drasticamente a mobilidade da população, $36 \%$ desses trabalhadores deixaram de trabalhar. Entre os motoristas que continuaram nas ruas, a média de horas trabalhadas por semana caiu de 45 para 20 horas em média.

O trabalho realizado por Castelo Branco et al. ${ }^{26}$ mostrou que $60,3 \%$ dos entrevistados indicou que houve diminuição da renda mesmo para aqueles que mantiveram a mesma carga horária, considerando-se os aumentos dos custos de combustível e seguros e o aluguel de veículos.

Os dados apresentados neste trabalho mostram que, dos 104 (100\%) participantes, $70(67,3 \%)$ relataram estar trabalhando desde o início da pandemia e que tiveram redução de carga horária e da renda mensal (entre 30 a $50 \%)$. Os dados podem conter um viés de comparação de antes e depois da pandemia, uma vez que 45 (43,3\%) deles relataram estar no negócio há apenas um ou dois anos.

Devido à queda abrupta e significativa de renda, 75 (72,1\%) motoristas solicitaram o auxílio emergencial do governo, que foi concedido a cerca de metade deles.

A preocupação com as medidas de higiene para prevenir a Covid-19 foi evidenciada neste estudo. Para diminuir o risco de contrair o vírus durante o trabalho, 70 (67,3\%) participantes informaram que adotaram medidas como uso de máscara, álcool em gel e lavagem do veículo com maior frequência. Mesmo assim, doze participantes da pesquisa apresentaram sintomas compatíveis com Covid-19, sendo quatro casos confirmados. Desses, três solicitaram o auxílio 
financeiro oferecido pela Uber, mas nenhum suporte financeiro foi obtido, deixando clara a distância entre discurso e prática da empresa.

O trabalho realizado por Silva et al. ${ }^{\mathbf{2 7}} \mathrm{em}$ amostra com 21 motoristas de aplicativos constatou que 15 deles $(71,4 \%)$ ofereciam álcool em gel para os passageiros e 19 (90,5\%) afirmaram utilizar máscara durante o trajeto, na presença do passageiro.

A empresa Uber divulgou um auxílio para higienização do veículo que permite ao 'motorista parceiro' o agendamento mensal e gratuito de uma limpeza do veículo com o produto Peroxy $4 \mathrm{D}^{28}$. Segundo dados divulgados pela fabricante Spartan, o Peroxy 4D tem alto desempenho e alcança amplo espectro de microrganismos, com ação bacteriostática de 72 horas $^{29}$. Segundo Maria Olímpia Rezende, doutora em química e professora da Universidade de São Paulo (USP) de São Carlos, o produto Peroxy 4D tem alto poder contra a Covid-19, porém tem durabilidade variável e que o mais importante e seguro é manter a desinfecção contínua dos veículos a cada doze horas ${ }^{29}$.

\section{Considerações finais}

A ‘uberização’ é sinônimo de precarização devido à falta de direitos trabalhistas e de proteção social, bem como da exploração do trabalho e, no caso dos aplicativos, de remuneração do trabalho sob demanda ou por corrida com passageiro. Este estudo, realizado durante a pandemia da Covid-19, evidenciou o aumento da precarização e o do risco de contaminação e do abandono dos 'motoristas parceiros' pelas empresas de aplicativos. Houve queda abrupta de cerca de $50 \%$ da renda devido à redução das chamadas e do valor da corrida sem a contrapartida de qualquer tipo de subsídio por parte da empresa por aplicativo. Para esses profissionais, o futuro do trabalho é desalentador, porque, no final de um dia de trabalho, o que se espera é sobreviver e não morrer. Esta pesquisa, realizada na pandemia, evidenciou o aumento da precarização e da vulnerabilidade do modelo de trabalho mediado por aplicativos. A sociedade contemporânea não pode aceitar esse tipo de exploração como futuro do trabalho.

\section{Colaboradores}

Greggo JP (0000-0002-4917-4162)* e Bandini M (0000-0003-2899-090X)* contribuíram para a concepção do estudo, desenvolvimento do projeto, aprovação no Comitê de Ética em Pesquisa, coleta de dados, análise dos dados e escrita do artigo. Lucca SR (0000-0001-60230949)* contribuiu para a concepção do estudo, desenvolvimento do projeto, análise dos dados e escrita do artigo. Azevedo V (0000-00015591-6516)* contribuiu para o desenvolvimento do projeto, análise dos dados e revisão do artigo. 


\section{Referências}

1. Abílio LC. Uberização: Do empreendedorismo para o autogerenciamento subordinado. Rev. Psicoperspec. 2019 [acesso em 2021 maio 20]; 18(3):1-11. Disponível em: https://scielo.conicyt.cl/scielo.php?pid=S0718$-69242019000300041 \&$ script=sci_arttext.

2. Abílio LC. Uberização do trabalho: a subsunção real da viração. 2017. [acesso em 2020 maio 21]. Disponível em: https://blogdaboittempo.com.br/2017/02/22/ uberizacao-do-trabalho-subsuncao-real-da-viracao/.

3. De Stefano V. The rise of the "just-in-time workforce": on-demand work, crowdwork and labour protection in the "gig-economy". Geneva: ILO; 2016. (Conditions of Work and Employment Series. N. 71) 2016. [acesso em 2021 maio 21]. Disponível em: https://www.ilo.org/wcmsp5/groups/public/---ed_ protect/---protrav/---travail/documents/publication/wcms_443267.pdf.

4. Oliveira F, Stedile J, Genoíno J. Classes sociais em mudança e a luta pelo socialismo. São Paulo: Perseu Abramo; 2000.

5. Agostini R, Scheffer ABB. Aplicativos de transporte privado como alternativa de renda: as vivências de trabalhadores e Uber em Porto Alegre. [dissertação]. Porto Alegre: Universidade Federal do Rio Grande do Sul. 2018. 17 p. [acesso em 2021 janeiro 23]. Disponível em: https://lume.ufrgs.br/handle/10183/189993.

6. Santos WJ, Cêlho VMS, Santas GB, et al. Sobrecarga de trabalho e comportamentos de risco em motociclistas. Rev Bras Enferm. 2019. [acesso em 2021 maio 21]; 72(6):1555-60. Disponível em: http://dx.doi. org/10.1590/0034-7167-2018-0279.

7. Uber Brasil. Dicas para motoristas. Afinal, qual é a nota mínima exigida pela Uber? 2019. [acesso em 2020 maio 21]. Disponível em: https://uberbra.com/ wp-content/cache/page_enhanced/uberbra.com// afinal-qual-e-a-nota-minima-exigida-pela-uber//index_ssl.html_gzip.
8. Antunes R, Praus L. A sociedade dos adoecimentos no trabalho. Serv. Soc. Soc. 2015. [acesso em 2021 maio]; (123):407-27. Disponível em: https://doi. org/10.1590/0101-6628.030.

9. Lucca SR. Trabalho e sofrimento psíquico: Histórias que contam esta história. São Paulo: Atarukas Editora Ltda; 2019.

10. Instituto Brasileiro de Geografia e Estatística. Desemprego cai para $11,8 \%$ com informalidade atingindo maior nível da série histórica. [acesso em 2021 jan 22]. Disponível em: https://censo2020.ibge.gov. br/2012-agencia-de-noticias/noticias/25534-desemprego-cai-para-11-8-com-informalidade-atingindo-maior-nivel-da-serie-historica.html.

11. Instituto Brasileiro de Geografia e Estatística. PNAD Contínua: Taxa de desocupação é de 14,1\% e taxa de subutilização é de $29 \%$ no trimestre encerrando em novembro de 2020. [acesso em 2021 fev 14]. Disponível em: https://www.agenciadenoticias.ibge.gov. br/agencia-sala-de-imprensa/2013-agencia-de-noticias/releases/29934-pnad-continua-taxa-de-desocupacao-e-de-14-1-e-taxa-de-subutilizacao-e-de-29-0-no-trimestre-encerrado-em-novembro-de-2020.

12. Correio Braziliense. Número de motoristas por aplicativo cresceu 136\% de 2012 a 2019. $2020 \mathrm{fev}$ 23. [acesso em 2021 jan 22]. Disponível em: https:// www.correiobraziliense.com.br/app/noticia/economia/2020/02/23/internas_economia,829826/ numero-de-motoristas-por-aplicativo-cresceu-136-de-2012-a-2019.shtml.

13. Fallavena LHA. Agora é que são elas: Trajetória de carreiras de mulheres motoristas de aplicativos de transportes. [dissertação]. Porto Alegre: Universidade Federal do Rio Grande do Sul. 2017. 73 p. [acesso em 2021 jan 18]. Disponível em: https://www.lume. ufrgs.br/handle/10183/169881.

14. Instituto de Certificação e Estudos de Trânsito e Transporte. Profissão motorista - mulheres ainda 
são minoria. 2020. [acesso em 2021 jan 24]. Disponível em: https://icetran.com.br/blog/motorista-mulheres-ainda-sao-minoria/.

15. Uber Brasil. Uber lança programa "Elas na direção" para incentivar mais mulheres a gerar renda dirigindo pelo app. 2019. [acesso em 2021 jan 24]. Disponível em: https://www.uber.com/pt-BR/newsroom/ uber-lanca-elas-na-direcao/.

16. Almeida FC. A "Lei do Uber" e o direito fundamental ao trabalho digno: análise da tramitação do projeto que deu origem à Lei no ${ }^{0} 13.649 / 18$ à luz das vulnerabilidades dos motoristas de aplicativos. Rev Eletr. Proc. Geral Est. Rio de Janeiro. 2020 [acesso em 2021 jan 23]; 3(1):1-35. Disponível em: https://revistaeletronica.pge.rj.gov.br:4432/comum/code/MostrarArquivo.php?C=MzM2.

17. Martins M, Almeida VH. Análise juslaboral da relação de trabalho entre motoristas por aplicativos e a empresa Uber: aspectos e consequências sociojurídicos. Rev. Direito Trab. Meio Amb. Trab. 2017 [acesso em 2021 maio 20];3(1):55-75. Disponível em: https://doi.org/10.26668/ IndexLawJournals/2525-9857/2017.v3i1.1812.

18. Gaulejac V. Gestão como doença social: ideologia, poder gerencialista e fragmentação social. Aparecida: Ideias \& Letras; 2007.

19. Franco DS, Ferraz DLS. Uberização do trabalho e acumulação capitalista. Cadernos Ebape.BR. 2019 [acesso em 2021 jan 24]; 17(esp):844-856. Disponível em: https://www.scielo.br/j/cebape/a/9NJd8xM hZD3qJVwqsG4WV3c/?format=pdf\&lang=pt.

20. Observatório Nacional de Segurança Viária. Violência no trânsito mata tanto quanto violência pública. 2019. [acesso em 2021 jan 25]. Disponível em: https:// www.onsv.org.br/observatorio-afirma-violencia-no-transito-tambem-e-violencia-.publica/.

21. Abílio LC. Uberização: a era do trabalhador just-in-time? Estud. av. 2020 [acesso em 2021 jan 25]; 34(98):111-26. Disponível em: https://doi.org/10.1590/ s0103-4014.2020.3498.008.
22. Portal G1. Assaltos a motoristas de aplicativo crescem 80,2\% em SP, apontam dados da Secretaria de Segurança. G1. 2019 nov 17. [acesso em 2021 jan 25]. Disponível em: https://gl.globo.com/sp/ribeirao-preto-franca/noticia/2019/11/17/assaltos-a-motoristas-de-aplicativo-crescem-802percent-em-sp-apontam-dados-da-secretaria-de-seguranca.ghtml.

23. Folha de São Paulo. 27\% dos sequestros relâmpagos são de motoristas de aplicativo. Folha de São Paulo. 2021 jan 2017. [acesso em 2021 jan 26]. Disponível em: https://agora.folha.uol.com.br/sao-paulo/2021/01/27-dos-sequestros-relampagos-sao-de-motoristas-de-aplicativo.shtml.

24. Aravanis G. Motorista de Uber é sequestrado e assaltado por falsos passageiros. 2020. [acesso em 2021 jan 26]. Disponível em: https://liberal.com.br/cidades/ americana/motorista-da-uber-e-sequestrado-por-falsos-passageiros-em-americana-1224867/.

25. Universidade Federal de Minas Gerais. Pandemia atinge em cheio os motoristas de aplicativos. 2020. [acesso em 2021 jan 25]. Disponível em: https://ufmg. br/comunicacao/noticias/covid-19-atinge-em-cheio-os-motoristas-de-aplicativo.

26. Castelo Branco PM, Comaru FA, Silva SJ. Uberização e covid-19: esgarçando as contradições do trabalho no século XXI. Rev Nov. Rumos soc. 2020. [acesso em 2021 maio 15]; 8(14):116-134. Disponível em: https:// periodicos.ufpel.edu.br/ojs2/index.php/NORUS/article/view/20035.

27. Silva RC, Santos BRP, Brito JF, et al. Motoristas de aplicativos em tempos de covid-19: tendências de informação e prevenção no contexto brasileiro. Rev eletr. Biblio. Ci. inf. 2021. [acesso em 2021 maio 15]; 26:01-21. Disponível em: https://www.redalyc.org/ articulo.oa?id=14768130009.

28. Uber Brasil. Uber lança centro de higienização para parceiros em São Paulo. 2020. [acesso em 2021 jan 30]. Disponível em: https://www.uber.com/pt-BR/ newsroom/uber-lanca-centro-de-higienizacao-para-parceiros-em-sao-paulo/. 
29. Peroxy D. Detalhes do produto. [acesso em 2021 jan 31]. Disponível em: http://www.spartanbrasil.com. br/produtos/detalhes/9/peroxy-4d.html\#top.

30. Alves S. Motoristas de App elogiam centro anticovid, mas reclama de preços. 2020. [acesso em 2021 jan 31]. Disponível em: https://www.uol.com.br/tilt/ noticias/redacao/2020/08/18/e-boa-mas-pode-melhorar-motoristas-de-apps-avaliam-limpeza-contra-covid.htm.

Recebido em 14/05/202

Aprovado em 12/11/2021

Conflito de interesses: inexistente

Suporte financeiro: não houve 